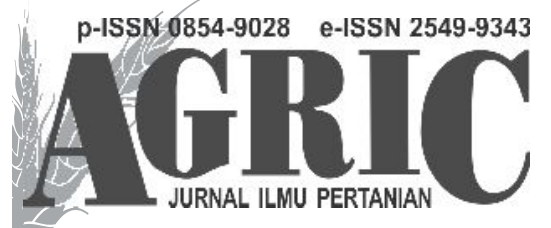

Fakultas Pertanian dan Bisnis Universitas Kristen Satya Wacana

Jl. Diponegoro 52-60 SALATIGA 50711 - Telp. 0298-321212 ext 354

email: jurnal.agric@adm.uksw.edu,website: ejournal.uksw.edu/agric

Terakreditasi Kementrian Riset, Teknologi dan Pendidikan Tinggi berdasarkan SK No 21/E/KPT/2018

EFEKTIVITAS PENGGUNAAN EM4 TERHADAP PERTUMBUHAN CABAI RAWIT (Capsicum frutescens L.)

\title{
THE EFFECTIVENESS OF EM4 USE ON GROWTH OF CAYENNE PEPPER (Capsicum frutescens L.)
}

\author{
Shalahuddin Mukti Prabowo ${ }^{1}$, Sangrani Annisa Dewi ${ }^{1},{ }^{2}$ Dwi Susilarto \\ ${ }^{1}$ Fakultas Pertanian, Jurusan Agroteknologi, Universitas Islam Batik Surakarta \\ ${ }^{2}$ PHP Tanaman Pangan dan Hortikultura, Sukoharjo \\ shalahuddinmp@gmail.com
}

Diterima 9 April 2018, disetujui 20 April 2018

\begin{abstract}
Cayenne pepper is one type of vegetables that have high economic value. Cayenne pepper as one of the many vegetable commodities cultivated by farmers in Indonesia because it has a high selling price. This study aims to analyze the effect of microbes by using EM4 on chili plants and assess the dose and time of EM4 application that is effective against the growth of cayenne pepper plant. The research method used was experiment, that is factorial experiment by using Randomized Complete Random Design (RAL) design with two treatment factors, EM4 dose (D): $D 1=5 \mathrm{ml} / \mathrm{L}, \mathrm{D} 2=105 \mathrm{ml} / \mathrm{L}, \mathrm{D} 3=20 \mathrm{ml} / \mathrm{L}$ and $E M 4$ (T) time: $T 1=5 \mathrm{HT}, \mathrm{T2}=10 \mathrm{HST}, \mathrm{T3}=$ 15 HST and. In total there are 10 treatment combinations with one control treatment (DOT0), with each treatment 3 plants and 3 replications, so there are 90 plants. The results showed that EM4 dosage with 15 days application time was the best combination of treatment for plant height, plant biomass and root length.
\end{abstract}

Keywords: Cayenne pepper Growth, EM4 Dose, EM4 Application Time 


\begin{abstract}
ABSTRAK
Cabai rawit merupakan salah satu jenis sayuran yang memilki nilai ekonomi tinggi. Cabai rawit sebagai salah satu komoditas sayuran banyak dibudidayakan oleh petani di Indonesia karena memiliki harga jual yang tinggi. Penelitian ini bertujuan untuk menganalisis pengaruh mikroba dengan menggunakan EM4 pada tanaman cabai dan mengkaji dosis dan waktu aplikasi EM4 yang efektif terhadap pertumbuhan tanaman cabai rawit. Metode penelitian yang digunakan adalah eksperimen, yaitu percobaan faktorial dengan menggunakan pola Rancangan Acak Lengkap (RAL) dengan dua faktor perlakuan yaitu dosis EM4 (D) : D1=5 ml/L, D2 = $105 \mathrm{ml} / \mathrm{L}, \mathrm{D} 3=20 \mathrm{ml} /$ L dan waktu pemberian EM4 (T): T1= 5 HT, T2 = 10 HST, T3= 15 HST. Satu sebagai perlakuan kontorl (D0T0) sehingga total ada 10 kombinasi perlakuan, dengan setiap perlakuan 3 tanaman dan 3 kali ulangan, sehingga ada 90 tanaman. Hasil penelitian menunjukkan bahwa Dosis EM4 dengan waktu aplikasi 15 hari sekali adalah kombinasi perlakuan yang paling baik terhadap tinggi tanaman, biomassa tanaman dan panjang akar.
\end{abstract}

Kata kunci: Pertumbuhan Cabai rawit, Dosis EM4, Waktu aplikasi EM4

\section{PENDAHULUAN}

Cabai (Capsicum frutescens L.) merupakan salah satu tanaman famili terung-terungan (Solanaceae). Tanaman ini termasuk golongan tanaman semusim atau tanaman yang berumur pendek. Asal tanaman ini dari daerah tropik Amerika dan telah tumbuh di Amerika Utara dan Selatan sejak 2000 tahun yang lalu. Cabai adalah sayuran utama di negara-negara Asia Tenggara. Di Indonesia, cabai merupakan sayuran dataran rendah yang paling penting, terutama dalam luasnya areal tanaman dan nilai produksinya. Kegunaan lebih khusus juga sebagai rempah-rempah, obat, penghias masakan, dan bahan pewarna makanan (Prajnanta 2008, Vos 1994).

Sebagai salah satu jenis sayuran, cabai merah memilki nilai ekonomi tinggi. Setiadi (2008) menambahkan dewasa ini cabai sebagai salah satu komoditas sayuran banyak dibudidayakan oleh petani di Indonesia karena memiliki harga jual yang tinggi dan dapat dimanfaatkan sebagai bahan campuran industri makanan, obatobatan dan peternakan. Selain itu kandungan vitamin $C$ yang cukup tinggi pada cabai dapat memenuhi kebutuhan harian pangan setiap orang yang mengkonsumsinya.

Kebutuhan cabai meningkat terus-menerus di setiap tahun sejalan dengan meningkatnya jumlah penduduk dan berkembangnya industri yang membutuhkan bahan baku cabai. Produksi cabai di Indonesia belum dapat memenuhi kebutuhan cabai nasional sehingga pemerintah harus mengimpor cabai yang mencapai lebih dari 16.000 ton per tahun. Ratarata produksi cabai nasional baru mencapai 4,35 ton/ha, sementara potensi produksi cabai dapat mencapai lebih 10 ton/ha (Direktorat Jenderal Bina Produksi Hortikultura, 2014).

Seiring dengan kebutuhan masyarakat yang terus meningkat dengan tidak diimbangi oleh ketersediaan komoditas cabai, maka berakibat pada harga produk cabai yang meningkat. Selain itu, harga yang meningkat juga disebabkan oleh lahan pertanian yang semakin menyempit dan petani cenderung menanam tanaman lain seperti padi, jagung, dan kacang-kacangan sehingga produktivitas cabai menurun sedangkan permintaan terus meningkat dan kenaikan harga terus terjadi. Perlu usaha khusus tentang 
bagaimana cara meningkatkan produksi cabai yang kebutuhannya selalu meningkat dari tahun ketahun.

Cara yang ditempuh oleh para petani untuk mengatasi kendala tersebut adalah dengan melakukan pemupukan menggunakan pupuk kimia. Namun, keberadaan pupuk kimia sering mengalami kelangkaan sehingga mengakibatkan harga yang melonjak tinggi. Dilihat dari kondisi tanah, penggunaan pupuk kimia berdampak pada pencemaran tanah, menurunkan $\mathrm{pH}$ tanah, cepat terserapnya zat hara dan dapat membuat tanah miskin akan unsur hara khususnya unsur hara mikro yang penting untuk meningkatkan hasil dan daya tahan tanaman terhadap serangan hama dan penyakit (Syaifudin et al., 2010).

Penggunaan mikroorganisme efektif (EM) merupakan salah satu teknologi yang dapat digunakan dalam usaha pengelolaan pertanian yang mampu mengurangi pengaruh negatif terhadap lingkungan. EM4 terdiri atas kultur campuran mikroorganisme bermanfaat dan hidup secara alami serta dapat diterapkan sebagai inokulum untuk meningkatkan keragaman mikroorganisme tanah dan tanaman (Higa \& Parr 1997). Oleh karena itu perlu dilakukan penelitian tentang bagaimana pengaruh penggunaan EM4 terhadap pertumbuhan. Penelitian ini bertujuan untuk menganalisis pengaruh mikroba dengan menggunakan EM4 pada tanaman cabai dan mengkaji dosis dan waktu aplikasi EM4 yang efektif terhadap pertumbuhan tanaman cabai rawit.

\section{METODE PENELITIAN}

Bahan yang digunakan adalah benih cabai yang sudah ditanam di pottray dengan usia siap tanam 21 hari dan tinggi $10 \mathrm{~cm}, \mathrm{EM} 4$, pupuk kandang, NPK. Alat yang digunakan adalah pottray, polybag, cangkul, ayakan, timbangan, meteran, dan alat tulis.

\section{Metode}

Penelitian ini dilaksanakan pada bulan AgustusOktober 2017, di Rumah Kaca milik Lab PHP Palur. Metode penelitian yang digunakan adalah eksperimen, yaitu percobaan faktorial dengan menggunakan pola Rancangan Acak Lengkap (RAL) dengan dua faktor perlakuan yaitu dosis EM4 (D) : D1 = $5 \mathrm{ml} / \mathrm{L}, \mathrm{D} 2=105 \mathrm{ml} / \mathrm{L}, \mathrm{D} 3=$ $20 \mathrm{ml} / \mathrm{L}$ dan waktu pemberian EM4 (T): T1= 5 HT, T2 $=10$ HST, T3= 15 HST. Satu sebagai perlakuan kontorl (D0T0) sehingga total ada 10 kombinasi perlakuan, dengan setiap perlakuan 3 tanaman dan 3 kali ulangan, sehingga ada 90 tanaman.

Variabel pengamatan yang diamati adalah: Pertumbuhan cabai rawit meliputi tinggi tanaman $(\mathrm{cm})$, biomassa tanaman $(\mathrm{g})$, dan panjang akar $(\mathrm{cm})$, produktivitas cabai meliputi jumlah buah dan berat buah (g). Data yang diperoleh dianalisis menggunakan analisis ragam (Annova) dengan uji taraf F 5\%, dan apabila terdapat beda nyata dilanjutkan dengan uji lanjut DMRT pada taraf 5.

\section{HASIL DAN PEMBAHASAN}

\section{Tinggi Tanaman Cabai Rawit}

\section{(C. frutescens, $\mathrm{L}$.}

Tingkat pertumbuhan tanaman cabai rawit (C. frutescens, L.) diukur setiap rentang waktu 2 minggu sekali dengan interval waktu 2, 4, 6 , $8,10,12$ minggu setelah tanam pada cabai rawit. Pengukuran pertumbuhan tanaman dilakukan dengan mengukur tinggi tanaman dari atas permukaan tanah hingga pucuk daun tertinggi. Pada saat panen, pertumbuhan diukur 
dengan menimbang biomassa tanaman dan mengkur panjang akar dari pangkal akar ke ujung akar yang paling panjang.

Parameter pertumbuhan tanaman diukur melalui tinggi tanaman, biomassa tanaman, dan panjang akar tanaman cabai rawit. Variabel tersebut diuji statistik untuk melihat pengaruh pemberian EM4. Berikut disajikan Gambar 1 tinggi tanaman, biomassa tanaman, dan panjang akar pada saat panen beserta penjelasan hasil uji statistiknya pada tanaman cabai rawit (C. frutescens $L$.).

Gambar 1 menunjukkan bahwa pemberian EM4 pada dosis pemupukan yang berbeda terhadap tinggi tanaman, biomassa tanaman, dan panjang akar cabai rawit (C. frutescens, L.) mempunyai nilai rata-rata yang berbeda. Pada pengamatan tinggi tanaman yang dilakukan, perlakuan pemberian EM4 dosis 15 $\mathrm{mL} / \mathrm{L}$ dengan waktu aplikasi $10 \mathrm{hr}$ sekali memiliki rata-rata tinggi tanaman tertinggi yaitu $76,78 \mathrm{~cm}$. Rata-rata tinggi tanaman terendah yaitu $71 \mathrm{~cm}$ pada tanpa perlakuan (kontrol) tanpa pemberian EM4. Dosis yang paling tepat dalam pemberian EM4 pada parameter tinggi tanaman cabai rawit (C. frutescens, L.) yaitu pada jenis perlakuan pemupukan EM4 dengan dosis $15 \mathrm{~mL} / \mathrm{L}$.

Hasil uji statistik menyatakan bahwa pertumbuhan pada tanaman cabai rawit ( $C$. frutescens, L.) dengan pemberian EM4, memiliki hasil yang tidak berbeda nyata pada parameter tinggi tanaman dengan pemberian EM4 dosis 5, 15, dan $25 \mathrm{ml} /$ tanaman. Berdasarkan data rerata tinggi tanaman, perlakuan pemberian EM4 dengan dosis $5 \mathrm{ml} /$ tanaman dapat menjadi alternatif pilihan untuk parameter tinggi tanaman. Parameter panjang akar tanaman cabai keriting (C. frutescens $\mathrm{L}$.) menunjukkan dosis optimal pemberian EM4 pada perlakuan dosis $5 \mathrm{ml} /$ tanaman. Hal ini menunjukkan EM4 mampu menyediakan unsur hara yang dibutuhkan oleh tanaman seperti $\mathrm{N}$, P, dan C (Campbell et al., 2003). Unsur-unsur tersebut terpenuhi dengan fungsi spesifik formulasi mikroba dalam EM4, yang terdiri dari Azotobacter sp., Azospirillum sp., Bacillus megaterium, Pseudomonas sp., dan Cellulomonas cellulans. Suplai hara yang

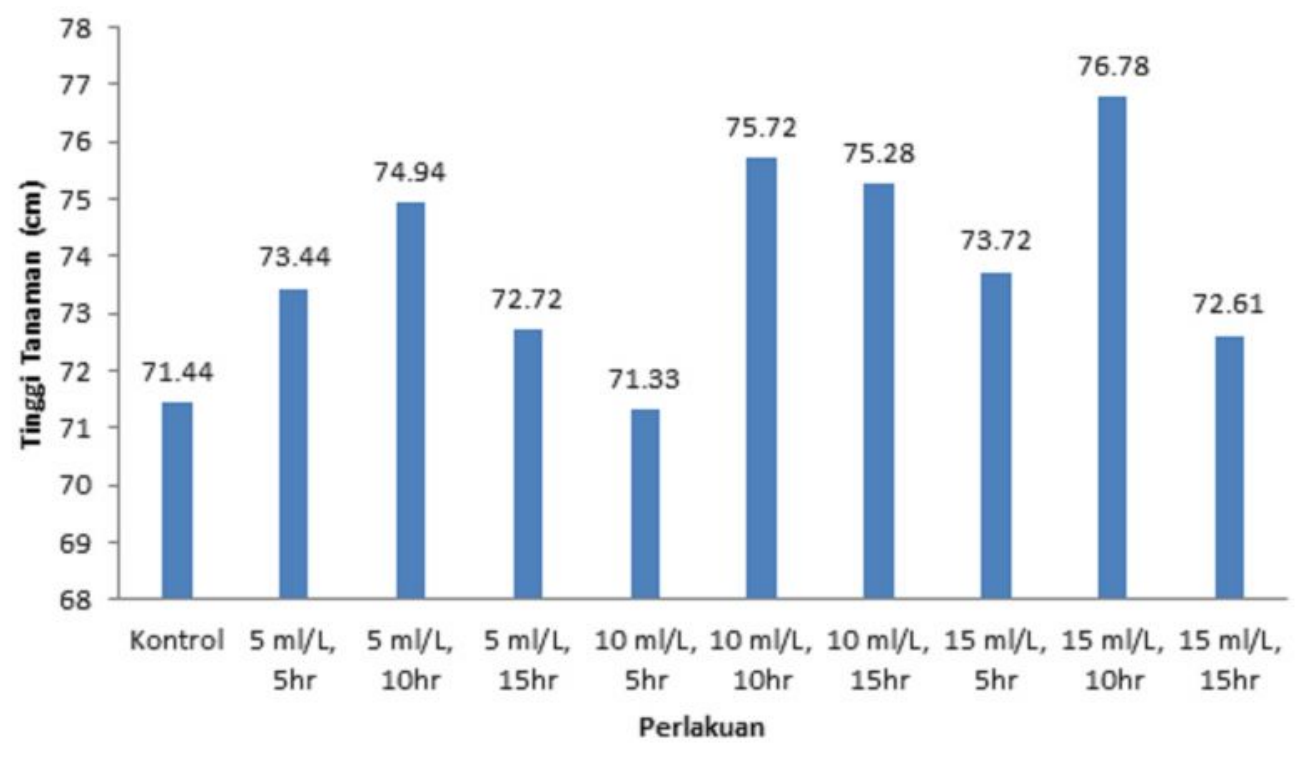

Gambar 1 Pengaruh perlakuan terhadap tinggi tanaman cabai rawit 
tercukupi membantu terjadinya proses fotosintesis dalam tanaman, yang menghasilkan senyawa organik yang akan diubah dalam bentuk ATP saat berlangsungnya respirasi, selanjutnya ATP digunakan tumbuhan untuk pertumbuhan tanaman (Campbell et al., 2003).

\section{Biomassa Tanaman Cabai rawit}

Hasil uji statistik pada variabel biomassa tanaman Cabai rawit menunjukkan hasil yang tidak berbeda nyata terhadap pemberian EM4 dosis 5,15 , dan $25 \mathrm{ml} /$ tanaman. Namun dari hasil pengamatan terhadap biomassa tanaman cabai rawit (C. frutescens $\mathrm{L}$.), yang dilakukan pada minggu ke 12 , menunjukkan bahwa pada perlakuan EM4 dengan dosis $10 \mathrm{~mL} / \mathrm{L}$ dan waktu aplikasi $15 \mathrm{hr}$ sekali memiliki rata-rata biomassa tanaman tertinggi yaitu $259,9 \mathrm{~g}$ (Gambar2). Rata-rata biomassa tanaman cabai rawit terendah yaitu 94,03 g pada tanpa perlakuan (kontrol). Dosis yang paling tepat dalam pemberian EM4 pada parameter biomassa tanaman cabai rawit (C. frutescens,
L.) yaitu pada perlakuan pemupukan EM4 dengan dosis $10 \mathrm{~mL} /$ tanaman.

Dosis yang lebih besar dibandingkan dengan parameter pertumbuhan yang lain yaitu pada tinggi tanaman dan panjang akar diduga karena pertumbuhan biomassa tanaman mencakup pertumbuhan primerdan sekunder. Pertumbuhan sekunder menyebabkan penebalan dibagian organ tumbuhan, sehingga nutrisi yang diperlukan juga lebih besar dan asupan energi untuk pertumbuhan juga lebih besar. Sehingga dosis yang dibutuhkan juga lebih besar. Pada tumbuhan berkayu, pertumbuhan primer dan sekunder terjadi pada waktu yang bersamaan, tetapi pada lokasi yang berbeda. Pertumbuhan primer hanya dibatasi pada bagian yang termuda, seperti ujung akar atau ujung tunas, di mana terdapat meristem apikal. Meristem lateral berkembang di daerah yang sedikit lebih tua pada akar tunas yang agak jauh dari ujung. Pada tempat tersebut terjadi pertumbuhan sekunder untuk menambah diameter organ. Bagian tertua dari akar dan tunas misalnya

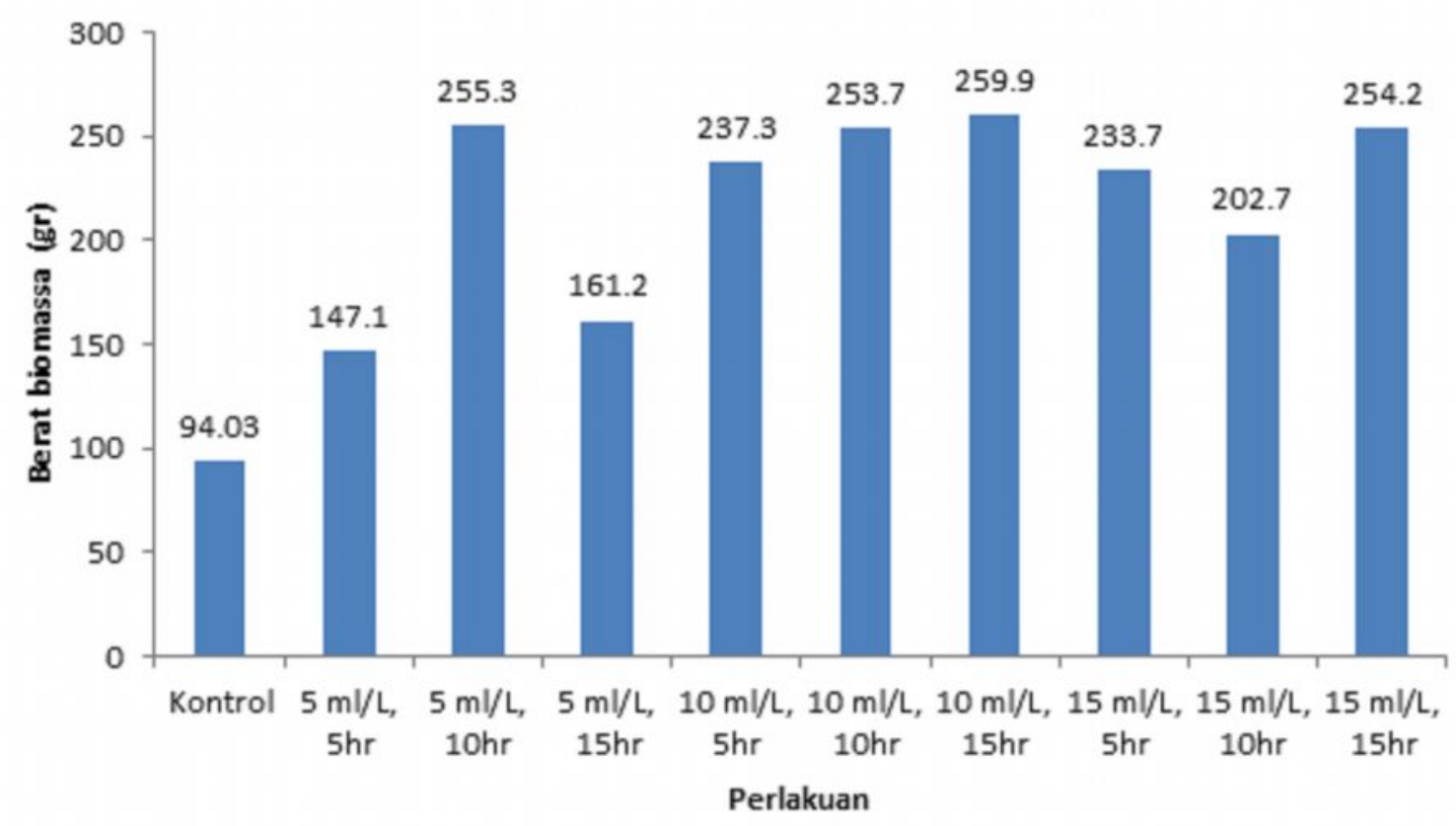

Gambar 2 Hasil pengamatan Biomassa tanaman Cabai rawit 
adalah pangkal cabang pohon, yang memiliki akumulasi jaringan sekunder yang paling besar dibentuk oleh meristem lateral. Setiap musim tumbuh, pertumbuhan primer menghasilkan perbesaran pada bagian muda pada akar tunas, sementara pertumbuhan sekunder menebalkan dan menguatkan bagian yang lebih tua dari tumbuhan tersebut (Campbell et al., 2003).

\section{Panjang akar tanaman Cabai rawit}

Pengamatan parameter panjang akar tanaman cabai rawit yang dilakukan pada minggu ke 12, perlakuan pemberian EM4 dengan dosis $10 \mathrm{~mL} / \mathrm{L}$ dan waktu aplikasi $15 \mathrm{hr}$ sekali memiliki rata-rata panjang akar tertinggi yaitu $25,73 \mathrm{~cm}$. Rata-rata panjang akar tanaman cabai rawit terendah yaitu $18,16 \mathrm{~cm}$ pada tanpa perlakuan (kontrol) tanpa pemberian EM4 (Gambar 3). Dosis yang paling tepat dalam pemberian EM4 untuk parameter panjang akar cabai rawit (C. frutescens, L.) yaitu perlakuan EM4 dengan dosis $10 \mathrm{~mL} / \mathrm{L}$.

Hasil penelitian menunjukkan bahwa jika dibandingkan pada tanpa perlakuan (kontrol) maka dapat dijelaskan hasilnya lebih rendah dan tanaman cenderung terkena penyakit (keriting) dari yang diberi perlakuan EM4. Kelebihan penggunaan EM4 karena dalam EM4 mengandung berbagai bakteri dan jamur, mempercepat pelarutan N, P, dan K. Ditilik dari tinggi tanaman pada umur 45 HST, respon tanaman dalam memanfaatkan unsur $\mathrm{N}$, $\mathrm{P}$, dan $\mathrm{K}$ beserta unsur hara mikro lainnya diduga telah tersedia dan tercukupi untuk pertumbuhan tanaman. Di samping itu kultur mikrobia yang ada di dalamnya dapat memperbaiki sifat fisik, kimia dan biologi tanah, khususnya tanah Entisol. Hal ini sesuai dengan pendapat Lingga (1994) menyatakan bahwa unsur nitrogen dan lainnya bagi tanaman dapat merangsang pertumbuhan tanaman secara keseluruhan khususnya batang dan daun, dengan sendirinya akan mempengaruhi performansi tinggi

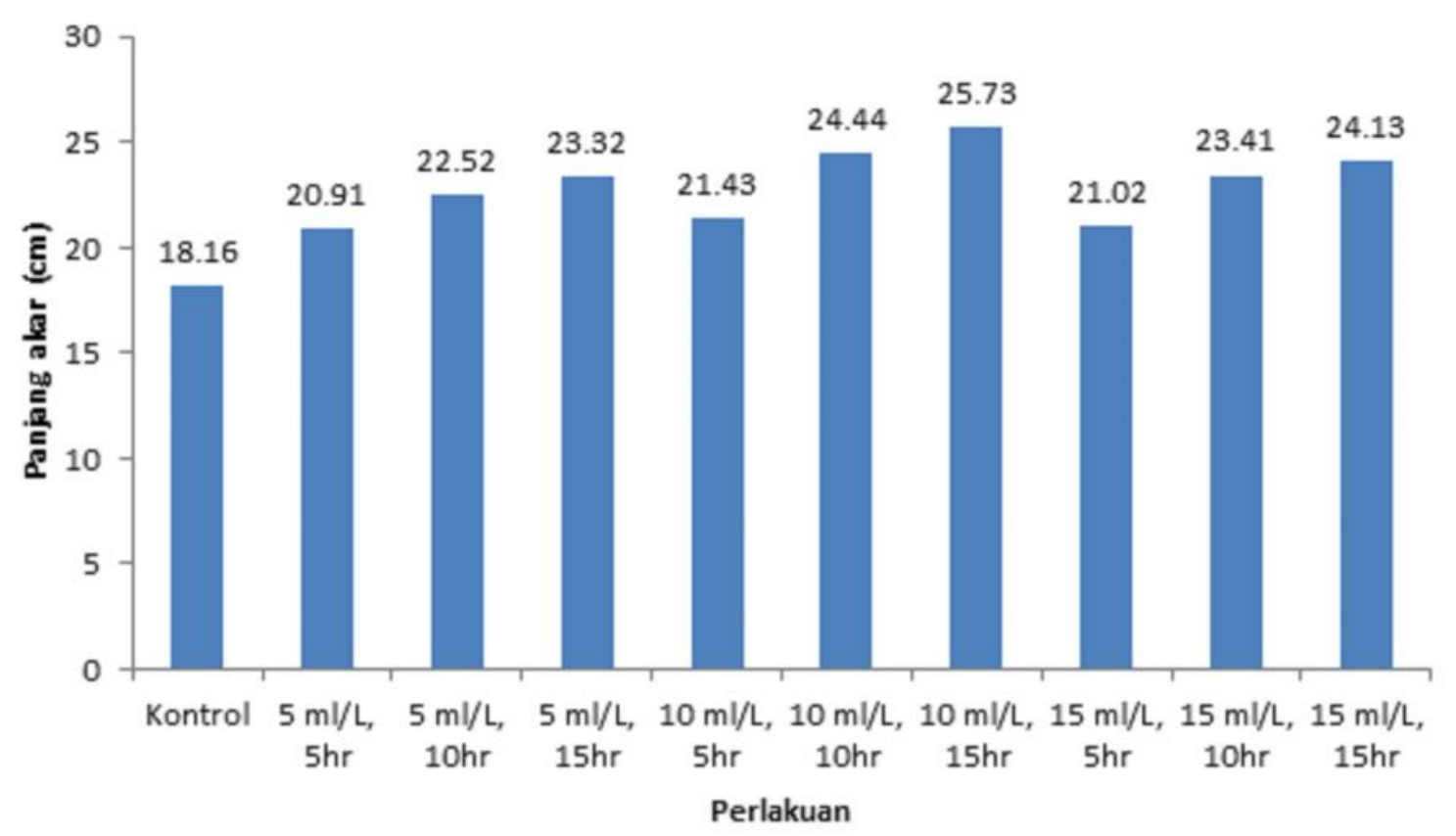

Gambar 3 Pengukuran panjang akar tanaman Cabai rawit 
tanaman. Selanjutnya Gardner et al. (1991) menambahkan bahwa secara umum penggunaan nitrogen pada tanaman mampu menghasilkan pertumbuhan vegetatif yang lebih cepat dan meningkatkan tinggi batang.

Dalam penelitian ini tinggi tanaman, biomassa tanaman serta panjang akar menunjukkan bahwa perlakuan konsentrasi EM4 tidak berpengaruh nyata. Hal ini diduga karena jumlah Nyang terkandung dalam EM4 belum tersedia dan diserap cukup untuk tanaman pada dan hal tersebut juga belum mampu memberi pengaruh pada biomassa tanaman.

Amir(2009) menambahkan bahwa penggunaan konsentrasi EM4 $30 \mathrm{ml} /$ liter air menghasilkan tinggi tanaman terbaik pada bibit mahoni dibandingkan dengan perlakuan yang lainnya. Hal ini sejalan dengan hasil penelitian ini, dimana pada konsentrasi EM4 tertinggi (E3) didapatkan hasil terbaik untuk tinggi tanaman dibandingkan dengan konsentrasi lainnya. Disisi lain, ketidakefektifan EM4 pada parameter lainnya diduga karena pada saat budidaya tanaman cabai terjadi pada musim kemarau dan kondisi tanah agak sedikit kering dibandingkan pada kondisi sesudah hujan (Siregar 1996). Ali (1996) menyatakan bahwa aplikasi EM4 belum mampu mensuplai hara secara optimal yang diperlukan tanaman. Hal ini diduga berkaitan dengan kinerja mikroorganisme dari EM4 yang tidak optimum.

Berdasarkan penelitian terdahulu mengenai penentuan dosis optimal dan waktu aplikasi EM4 terhadap pertumbuhan dan produktivitas cabai rawit oleh Syafruddin dan Syafrizal (2013) menyatakan bahwa dosis optimal pada saat panen dengan indikator tinggi tanaman ditunjukkan oleh perlakuan dosis $15 \mathrm{ml} / \mathrm{L}$ dengan frekuensi pemupukan 2 minggu sekali.
Hal ini sesuai dengan hasil penelitian yang memberi hasil terbaik pada parameter tinggi tanaman dan panjang akar, namun berbeda pada parameter biomassa tanaman.

Penelitian terdahulu yang telah dilakukan oleh Berova et al. (2010) mengenai efek dari EM4 terhadap pertumbuhan dan produktivitas tanaman cabai (C. frutescens $L$.), menunjukkan bahwa perlakuan dengan EM4 memberi hasil yang lebih baik dibandingkan dengan kontrol. Parameter tinggi tanaman dan diameter mahkota memiliki nilai yang lebih besar dibandingkan dengan kontrol. Jumlah, ukuran daun, dan massa tanaman juga meningkat dibandingkan dengan kontrol. Hal ini dapat terjadi karena adanya perbaikan nutrisi dan akumulasi hasil fotosintat untuk pertumbuhan dari tanaman yang diberi perlakuan EM4. Selain itu, perlakuan dengan EM4 juga memberi pengaruh yang lebih baik pada tanaman cabai dari aspek generatif tanaman (Saharan dan Nehra, 2011). Hal ini menunjukkan bahwa perlakuan dengan EM4 memiliki pengaruh yang lebih baik pada pertumbuhan tanaman sesuai dengan penelitian kali ini.

\section{KESIMPULAN}

Dosis EM4 $10 \mathrm{ml} / \mathrm{L}$ dengan waktu aplikasi 15 hari sekali adalah kombinasi perlakuan yang paling baik terhadap tinggi tanaman, biomassa tanaman dan panjang akar. Hasil analisis uji $\mathrm{F}$ menunjukkan bahwa perlakuan yang diberikan tidak berbeda nyata terhadap variabel pengamatan.

\section{DAFTAR PUSTAKA}

Ali, M. 1996. Pengaruh aplikasi Effective Microorganisms 4 (EM4) dan pupuk kandang terhadap produksi dan viabilitas benih cabai. Karya Ilmiah. 
Jurusan Budidaya Pertanian, Fakultas Pertanian, IPB. Bogor.

Amir, S. 2009. Konsentrasi Mikro-organisme Efektif 4 (EM4) dan Dosis Azolla terhadap Pertumbuhan Bibit Mahoni (Swietenia macrophylla K.). Research Report. Universitas Muhamadyah Malang, Malang.

Berova, Malgorzatta.,Georgios Karanatsidis., Krasimira Sapundzhieva, dan Veselina Nikolova. 2010. Effect of organic fertilization on growth and yield of pepper plants (Capsicum annuum L.). Journal Folia Horticulturae Ann. 22 (1) : 3-7.

Cahyono, B. 2003. Cabai Rawit. Kanisius. Yogyakarta.

Cahyono, B. 2008. Teknik Budidaya Cabai Rawit dan Analisis Usaha Tani. Kanisius. Yogyakarta.

Campbell, N.A., J.B. Reece, dan L.G. Mitchell. 2003. Biologi Jilid 2 Edisi Kelima. Erlangga. Jakarta.

Direktorat Jenderal Bina Produksi Hortikultura [DBPH]. 2014. Luas panen, Rata-rata Hasil dan Produksi Tanaman Hortikultura di Indonesia. Departemen Pertanian. Jakarta.

Gardner, F. P., R. B. Pearce, \& R. L. Mitchell. 1991. Fisiologi Tanaman Budidaya (alih bahasa H. Susilo). Universitas Indonesia Pers. Jakarta

Higa, T. \& J.F. Parr. 1997. Effective Microorganism (EM-4) untuk Pertanian dan Lingkungan yang Berkelanjutan. Indonesian Kyusei Nature Farming Societies. Jakarta.
Lingga, P. 1994. Petunjuk Penggunaan Pupuk. Penebar Swadaya. Jakarta.

McMilan, S. 2007. Promoting growth with $P G P R$. The Canadian Organic Grower. Soil Foodweb Canada Ltd. Soil Biology Lab. \&Learning Centre. p. 32-34.

Prajnanta, F. 2008. Agribisnis Cabai Hibrida. Penebar Swadaya. Jakarta.

Rai, M. K. Ed. 2006. Handbook of Microbial EM4s. Food Products Press-The Haworth Press Inc. New York

Rao, N.S.S. 1994. Mikroorganisme Tanah dan Pertumbuhan Tanaman. Edisi Kedua. UI Press. Jakarta

Saharan, B S., Nehra, V. 2011. Plant Growth Promoting Rhizobacteria: A Critical Review. J. Life Science and Medicine Research. 20 (1): 11-21

Setiadi. 2008. Bertanam Cabai (edisi revisi). PT. Penebar Swadaya. Jakarta.

Simanungkalit, R.D.M., D.A. Suriadikarta, R. Saraswati, D. Setyorini, dan W Hartatik. 2006. Pupuk Organik dan Pupuk Hayati. Balai Besar Litbang Sumberdaya Lahan Pertanian. Bogor.

Siregar., E.R., Melinda. 1996. Pengaruh aplikasi Effective Microorganisms 4 (EM4) terhadap pertumbuhan bibit the (Camellia sinensis (L.) O. Kuntze) Klon MPS7 dan Gmb5. Karya Ilmiah. Jurusan Budidaya Pertanian, Fakultas Pertanian, IPB. Bogor.

Steenis, C.G.G.J.V. 2002. Flora. Cetakan ke delapan. Pradnya Paramita. Jakarta

Sturz, A.V., and Nowak, J. 2000. Endophytic communities of rhizobacteria and the strategies required to create yield 
enhancing associations with crops. Appl. Soil Ecol. 15:183-190.

Syaifudin, A., L. Mulyani, M. Ariesta. 2010. Pupuk Kosarmas sebagai Upaya Revitalisasi Lahan Kritis Guna Meningkatkan Kualitas dan Kuantitas Hasil Pertanian. Universitas Negeri Sebelas Maret. Surakarta.

Syafruddin dan Safrizal HD. 2013. Pengaruh Konsentrasi dan Waktu Aplikasi Em4 Terhadap Pertumbuhan dan Produksi Cabai (Capsicum Annum L.) Pada Tanah Entisol. Jurnal Agrista. 17 (2): 71-77.
Tjandra, E. 2011. Panen Cabai Rawit di Polybag. Cahaya Atma Pustaka. Yogyakarta.

Vos, J. G. M. 1994. Pengelolaan Tanaman Terpadu pada Cabai (Capsicum annum L.) di Dataran Rendah Tropis (terjemahan). Universitas Pertanian Wageningen.

Wididana, G.N. 1994. Peranan Effective Microorganism-4 dalam Meningkatkan Kesuburan dan Produktivitas Tanah. Indonesian Kyusei Nature Farming 
